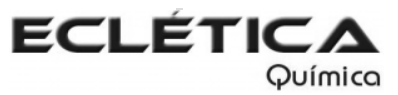

www.scielo.br/eq

Volume 31, número 1, 2006

\title{
Otimização de ELISA empregando a proteína Tc85-11 e planejamento fatorial
}

\author{
T. B. Zanoni , I. Z. Carlos ${ }^{2}$, J. O. Tognolli ${ }^{3}$, H. Yamanaka ${ }^{3}$, A. A. P. Ferreira ${ }^{3 *}$ \\ ${ }^{\prime}$ Centro Univ. Barão Mauá, Faculdade de Ciências Farmacêuticas, Ribeirão Preto (SP), Brasil; \\ ${ }^{2}$ Unesp, Faculdade de Ciências Farmacêuticas, Araraquara (SP), Brasil; \\ ${ }^{3}$ Unesp, Instituto de Química, Araraquara (SP), Brasil \\ *antoferr@posgrad.iq.unesp.br
}

Resumo: A doença de Chagas é causada pelo Trypanosoma cruzi (T. cruzi) e a detecção de anticorpos anti-T. cruzi no soro é um método para diagnosticar a doença. Neste trabalho, ELISA indireto foi otimizado para a detecção de anticorpos no soro de pacientes com doença de Chagas empregando a proteína Tc85-11 (Ag) da superfície do parasita tripomastigota. Na otimização das condições experimentais foi aplicado planejamento fatorial completo para os parâmetros tempo de incubação, diluições do $\mathrm{Ag}\left(0,08 \mathrm{mg} \mathrm{mL}^{-1}\right)$, anticorpo primário (Ac) e anti-IgG conjugada com a peroxidase $\left(\mathrm{Ac}^{*}\right)$. Os melhores resultados foram obtidos nas seguintes condições: $0,14 \mathrm{mg}$ Ag/poço, 60 min para o tempo de incubação, diluições de 1:35 e 1:1000 para Ac e Ac*, respectivamente. O valor do limiar de reatividade ("cut off") foi $\mathrm{A}_{450 \mathrm{~nm}}=0,371$. O ELISA indireto foi aplicado em amostras de soros de pacientes infectados com doença de Chagas e pacientes com diferentes doenças sistêmicas. A proteína Tc85-11, a qual está envolvida com a adesão do parasita na célula hospedeira, é também apropriada para o diagnóstico sorológico da doença de Chagas.

Palavras-chave: T. cruzi; Tc85-11; ELISA; doença de Chagas.

\section{Introdução}

A doença de Chagas é um relevante problema de saúde pública na América do Sul, Central e México. Estima-se que 16-18 milhões de pessoas estão infectadas e cerca de $25 \%$ da população da América Latina estão sob o risco de contrair a infecção, de acordo com a Organização Mundial de Saúde [1]. A doença é causada por um protozoário flagelado, Trypanosoma cruzi ( $T$. cruzi), que possui três formas em seu ciclo de vida: epimastigota, amastigota (forma proliferativa) e tripomastigota (forma invasiva nas células).
A transmissão da doença pode ocorrer através de insetos hematófagos ("barbeiros"), transfusão sanguínea, via congênita, transplantes de órgãos e inoculação acidental em laboratório [2]. As afecções que causam são cardíacas, digestivas e/ou neurológicas, que variam segundo as regiões da América e os indivíduos infectados [3].

O diagnóstico laboratorial da infecção pelo $T$. cruzi pode ser realizado por meio da busca do parasita ou da resposta imune do hospedeiro infectado empregando-se habitualmente sangue venoso. A detecção de anticorpos anti-T. cruzi na pesquisa sorológica é o método de escolha para o 
diagnóstico etiológico da doença de Chagas na fase crônica, considerando a especificidade e a sensibilidade dos testes empregados na rotina de análises clínicas, embora apresente algumas limitações inerentes à sua própria natureza. $\mathrm{Na}$ fase aguda da doença de Chagas, anticorpos das classes IgM e IgG são detectáveis e na fase crônica, anticorpos da classe IgG [4]. Os níveis de reatividade diferem para cada método e de acordo com a finalidade de diagnóstico. Dentre os testes sorológicos mais utilizados durante a fase crônica, destaca-se o teste imunoenzimático ELISA ("Enzyme Linked Immunosorbent Assay") cabendo a Voller et al. [5] a sua aplicação na determinação de anticorpos anti-T. cruzi.

A literatura tem registrado diferentes antígenos no teste sorológico ELISA para doença de Chagas, por exemplo, antígenos não-purificados [6], purificados [7], secretado-excretado [8] e recombinantes $[9,10]$.

A partir da superfamília das gp85/trans-sialidases, componente da superfície do parasita, Marroquin-Quelopana Jr. et al. descobriram uma das moléculas da forma tripomastigota do T. cruzi (Tc85-11) pertencentes à família Tc-85 [11]. Esta importante molécula está caracterizada como molécula de adesão e internalização do parasita à célula hospedeira. A proteína Tc85-11 foi empregada no desenvolvimento de imunossensor amperométrico para a detecção de anticorpos anti-T. cruzi em soros de pacientes chagásicos [12]. Os resultados demonstraram que a proteína Tc85-11 é também um antígeno que reage com o anticorpo anti-T. cruzi.

Considerando a importância dos testes sorológicos na prática clínica para o diagnóstico da doença de Chagas, o presente estudo refere-se ao emprego da proteína recombinante purificada Tc85-11 de T. cruzi com aplicação de planejamento fatorial completo na otimização de ELISA indireto. Atualmente, na otimização de métodos analíticos, o planejamento fatorial tem sido bastante utilizado para avaliar a significância das variáveis, bem como indicar as melhores condições para obtenção dos melhores resultados [13-15].

\section{Materiais e métodos}

A proteína Tc85-11 (0,08 mg mL-1) gentil- mente cedida por Walter Colli e Maria Júlia M. Alves (Instituto de Química da USP, São Paulo) foi sintetizada, purificada por cromatografia de afinidade e sua pureza verificada em gel de poliacrilamida-SDS 9\% por Débora R. Oliveira [16]. Os ensaios foram realizados em tiras de poliestireno de 96 poços (Corning, NY), mediante titulação nas diferentes etapas do teste imunoenzimático e feita a leitura espectrofotométrica a 450 $\mathrm{nm}\left(\mathrm{A}_{450}\right)$ em leitor de ELISA (Organon Teknika).

O procedimento analítico do teste qualitativo do antígeno recombinante Tc85-11 de T. cruzi por imunoensaio ELISA consistiu no seguinte: a) Aplicação de $100 \mathrm{~mL}$ da amostra protéica diluída em solução tampão bicarbonato $0,05 \mathrm{~mol} \mathrm{~L}^{-1}, \mathrm{pH}$ 9,6, nos poços ("well") da placa de ELISA e esta incubada à $4^{\circ} \mathrm{C}$ durante 18 horas; b) Lavagem com PBS-T 0,05\%, três vezes de 60 segundos; d) Após escoamento, cada poço recebeu $100 \mathrm{~mL}$ de solução PBS-T $0,05 \%$ contendo $5 \%$ de leite desnatado (Nestlé), com incubação a $37^{\circ} \mathrm{C}$, durante 60 minutos; lavagem dos poços conforme item b; d) Os poços sensibilizados com o antígeno Tc85-11 de $T$. cruzi receberam $100 \mathrm{~mL}$ do soro controle positivo diluído em solução de bloqueio e incubados a $37^{\circ} \mathrm{C}$, durante 30 ou 60 minutos; e) Lavagem dos poços conforme item b; f) Aplicação de $100 \mathrm{~mL}$ da solução contendo anticorpos monoclonais antiIgG humana conjugado com peroxidase (IgG humana conjugada com enzima Horseradish Peroxidase, Sigma-Aldrich) (1,66 mg de proteínas por $\mathrm{mL}$ ) diluída em solução de bloqueio e incubação a $37^{\circ} \mathrm{C}$, durante 30 ou 60 minutos; lavagem dos poços conforme item b; g) Adição de $100 \mathrm{~mL}$ das soluções de TMB (tetrametilbenzidina) e peróxido de hidrogênio na proporção de 1:1 e incubação de 10 minutos na ausência de luz e à temperatura ambiente; h) Adição de $100 \mathrm{~mL}$ de solução ácido sulfúrico $1 \mathrm{~mol} \mathrm{~L}^{-1}$ e leitura espectrofotométrica das tiras.

A otimização do ELISA indireto foi dividida em etapas, sendo a primeira relacionada com a avaliação das melhores diluições do antígeno $(\mathrm{Ag})$, anticorpos primário (Ac) e secundário (Ac*) a partir de estudos preliminares, enquanto que na segunda etapa do planejamento experimental definiu-se o melhor tempo de incubação e limiar de reatividade para o imunoensaio. Em ensaios preliminares avaliaram-se as diluiçõos do Ag, Ac e 
Ac* utilizando planejamento fatorial $2^{3}$ em triplicata, com 3 variáveis ( $\left.\mathrm{Ag}, \mathrm{Ac}, \mathrm{Ac}^{*}\right)$ em dois níveis de variação. Os níveis de variação foram de 0,14 e 0,20 mg/poço para o Ag de T. cruzi, diluições de 1:40 e 1:80 para o Ac e de 1:1000 e 1:2000 para o anticorpo conjugado com peroxidase; nas etapas de incubação o tempo foi de 60 minutos. Para melhor definir as diluições ideais das variáveis (Ag, Ac e Ac*) foi empregado o tipo de planejamento composto central, resultando 20 experimentos, em duplicata. O planejamento composto central utilizado nesse trabalho compreende o planejamento estatístico fatorial $2^{3}$, ponto central e o delineamento em estrela [13]. Na definição do melhor tempo de incubação do imunoensaio ELISA empregou-se planejamento fatorial $2^{2}$ em duplicata, com 2 variáveis $\left(\mathrm{t}_{\mathrm{Ac}}\right.$ : tempo de incubação para o Ac; $\mathrm{t}_{\mathrm{Ac}}$ : tempo de incubação para o $\mathrm{Ac}^{*}$ ), resultando 4 experimentos. É importante ressaltar que a ordem de realização dos experimentos foi definida aleatoriamente. A significância dos efeitos das variáveis e das possíveis interações entre elas foi analisada estatisticamente utilizando a análise de variância (ANOVA) e com base nos gráficos de Pareto (Figuras 1 e 3). Os valores dos efeitos principais e de interação (valor de P) foram calculados empregando o programa estatístico MINITAB Statistical Software Release 13.

Após a otimização dos parâmetros experimentais, empregou-se para a prova sorológica ELISA um "pool" de soros positivos $(\mathrm{n}=10)$ como controle positivo e 10 soros controles negativos para Chagas na determinação do limiar de reatividade. Os soros controles positivos e negativos, confirmados pelas técnicas convencionais em sorologia (ELISA e imunofluorescência indireta), provenientes de uma soroteca e sem identificação dos pacientes correspondentes às amostras foram cedidos pelo Laboratório de Sorologia da Faculdade de Ciências Farmacêuticas da Unesp. O limiar de reatividade foi determinado a partir da média aritmética das densidades ópticas das amostras de soros negativos acrescida de duas vezes o desvio médio das densidades ópticas e uma zona de indeterminação de $\pm 20 \%$.

Procedeu-se os ensaios com 3 amostras de soros positivos para Chagas ( $\mathrm{S} 1+, \mathrm{S} 2+$ e $\mathrm{S} 3+)$ e na determinação de reações cruzadas com soros de pacientes com doenças inflamatórias ou infec- ciosas crônicas: 3 soros de leishmaniose sp (L1, L2 e L3), 1 artrite reumatóide (A), 1 esquistossomose $(\mathrm{E}), 1$ hanseníase $(\mathrm{H})$ e 1 paracoccidioidomicose $(\mathrm{P})$ expedidos pelo Instituto Adolf Lutz (São Paulo, SP), Instituto Lauro de Souza Lima (Bauru, SP) e Faculdade de Ciências Farmacêuticas da Unesp (Araraquara, SP).

\section{Resultados e discussão}

Investigações preliminares indicaram que as melhores tendências obtidas no planejamento fatorial $2^{3}$ foram nas diluições de 0,14 mg/poço, 1:40 e 1:1000 para o Ag de T. cruzi, Ac e Ac*, respectivamente. A partir dos resultados do fatorial $2^{3}$, executou-se o planejamento central composto com 06 repetições de ensaios no ponto central.

Verifica-se na Tabela 1 a matriz dos valores empregados no planejamento composto central e os resultados das leituras de absorbância $\left(\mathrm{A}_{450}\right)$ desta etapa de experimentos para definir as diluições ideais das variáveis: $\mathrm{Ag}$ (mg/poço), Ac e Ac*. Na Tabela 2 são apresentados os valores estatísticos na análise das diluições das variáveis $(\mathrm{Ag}, \mathrm{Ac}$ e $\mathrm{Ac} *)$ isoladas e combinadas e na Figura 1 o gráfico de Pareto para o planejamento composto central.

Para as diluições do Ag, Ac e Ac* (Figura 1) a variável significativa foi o antígeno $(\mathrm{Ag})$ e o seu termo quadrático. A Figura 2 representa os gráficos de superfície de respostas tridimensionais e de contornos bidimensionais obtidos para as interações das variáveis estudadas a partir do planejamento composto central. Cada contorno corresponde a uma altura particular da superfície de resposta e em cada linha a resposta foi constante. Observa-se visualmente nos gráficos de superfícies tridimensionais que a resposta no ponto ótimo foi o ponto máximo. Examinando os gráficos de contornos, pode-se verificar que o processo foi sensível às mudanças das variáveis e que a melhor resposta se encontra na região central do elipsóide com maior altura da superfície de resposta. Verificou-se que as melhores condições para as diluições do Ag Tc85-11 de $T$. cruzi, Ac e Ac* foram 0,14 mg/poço, 1:35 e $1: 1000$, respectivamente. 
Tabela 1. Matriz de planejamento composto central e valores de absorbância em ELISA empregando o antígeno Tc85-11.

\begin{tabular}{cccccc}
\hline $\begin{array}{c}\mathrm{N}^{\mathrm{o}} \\
\text { Ensaios }\end{array}$ & $\mathrm{Ag}$ & $\mathrm{Ac}$ & Ac* & $\begin{array}{c}\text { Resultado } \\
(\text { média) } \\
\mathrm{A}_{450}\end{array}$ & Desvio Padrão \\
\hline 1 & 0,12 & $1: 30$ & $1: 500$ & 0,523 & \\
\hline 2 & 0,16 & $1: 30$ & $1: 500$ & 0,492 & 0,047 \\
3 & 0,12 & $1: 50$ & $1: 500$ & 0,301 & 0,046 \\
4 & 0,16 & $1: 50$ & $1: 500$ & 0,369 & 0,015 \\
5 & 0,12 & $1: 30$ & $1: 1500$ & 0,323 & 0,024 \\
6 & 0,16 & $1: 30$ & $1: 1500$ & 0,342 & 0,020 \\
7 & 0,12 & $1: 50$ & $1: 1500$ & 0,251 & 0,037 \\
8 & 0,16 & $1: 50$ & $1: 1500$ & 0,261 & 0,031 \\
9 & 0,11 & $1: 40$ & $1: 1000$ & 0,577 & 0,026 \\
10 & 0,17 & $1: 40$ & $1: 1000$ & 0,533 & 0,008 \\
11 & 0,14 & $1: 23$ & $1: 1000$ & 1,192 & 0,124 \\
12 & 0,14 & $1: 57$ & $1: 1000$ & 0,753 & 0,046 \\
13 & 0,14 & $1: 40$ & $1: 159$ & 1,279 & 0,087 \\
14 & 0,14 & $1: 40$ & $1: 1840$ & 0,729 & 0,063 \\
15 & 0,14 & $1: 40$ & $1: 1000$ & 0,938 & 0,102 \\
16 & 0,14 & $1: 40$ & $1: 1000$ & 0,870 & 0,018 \\
17 & 0,14 & $1: 40$ & $1: 1000$ & 0,914 & 0,054 \\
18 & 0,14 & $1: 40$ & $1: 1000$ & 0,814 & 0,053 \\
19 & 0,14 & $1: 40$ & $1: 1000$ & 0,954 & 0,118 \\
20 & 0,14 & $1: 40$ & $1: 1000$ & 0,864 & 0,061 \\
\hline
\end{tabular}

* Ensaios realizados em duplicata

Tabela 2. Valores estatísticos para os principais efeitos e as interações do planejamento composto central.

\begin{tabular}{ccc}
\hline Variável & $\mathrm{T}$ & $\mathrm{P}$ \\
\hline $\mathrm{Ag}$ & 2,665 & 0,024 \\
$\mathrm{Ac}$ & 0,390 & 0,705 \\
$\mathrm{Ac} *$ & 0,063 & 0,951 \\
Ag.Ag & 2,948 & 0,015 \\
Ac.Ac & 0,981 & 0,350 \\
Ac*.Ac* & 0,831 & 0,426 \\
Ag.Ac & 0,112 & 0,913 \\
Ag.Ac* & 0,010 & 0,992 \\
Ac.Ac* & 0,240 & 0,815 \\
\hline
\end{tabular}

$\mathrm{T}=$ Teste $\mathrm{T}$ (Gráfico de Pareto)

$\mathrm{P}=$ Probabilidade
Após definir as diluições do Ag, Ac e Ac*, procedeu-se o planejamento fatorial $2^{2} \mathrm{com} 2$ variáveis (tempo de incubação de 30 ou 60 minutos para o Ac $\left(\mathrm{t}_{\mathrm{Ac}}\right)$ e para o Ac* $\left(\mathrm{t}_{\mathrm{Ac}}\right)$. Observase pela Tabela 3 a matriz dos valores empregada no planejamento fatorial $2^{2}$ e os resultados das leituras de absorbância $\left(\mathrm{A}_{450}\right)$ desta etapa de experimentos para melhor definir o tempo de incubação do imunoensaio ELISA. Na Tabela 4 são mostradas os valores estatísticos para os efeitos principais e as interações e na Figura 3 o gráfico de Pareto para o planejamento fatorial $2^{2}$.

$\mathrm{Na}$ definição do melhor tempo de incubação, foram variáveis significativas os tempos de incubação para ambos os anticorpos (Ac e $\mathrm{Ac}^{*}$ ) e a interação entre elas conforme apresentado na Figura 3. A Figura 4a representa 


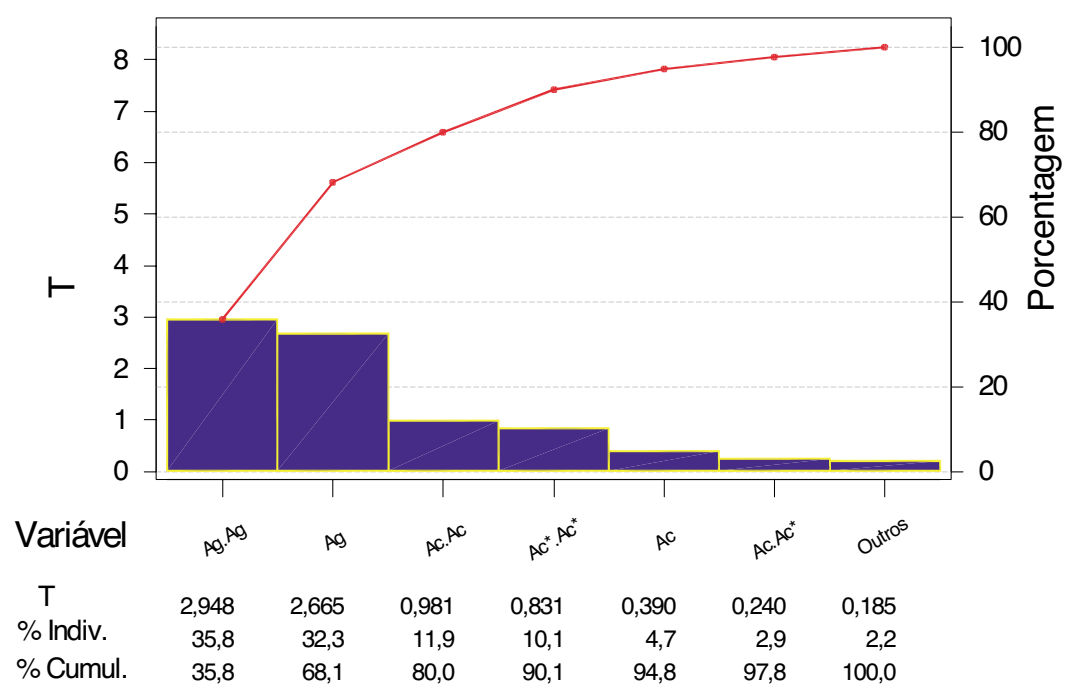

Figura 1. Gráfico de Pareto do planejamento composto central obtido para diluições Ag, Ac e Ac* (a linha vertical representa a porcentagem cumulativa das variáveis).

os gráficos de efeitos principais, empregando planejamento fatorial $2^{2}$, para o fator tempo de incubação dos anticorpos primário e secundário. Esse gráfico linear ilustra a variação média das respostas em função da mudança do tempo de incubação, mantendo constantes as diluições do $\mathrm{Ag}, \mathrm{Ac}$ e Ac* definidas no planejamento central composto. Os resultados mostraram que essas interações ocorrem melhor com o tempo de 60 min em ambas as etapas de incubação do imunoensaio. A Figura $4 \mathrm{~b}$ mostra os efeitos de interação para os tempos de incubação $\left(t_{A c} e t_{A c^{*}}\right)$ sobre o imunoensaio ELISA e demonstra que o efeito provocado pela mudança do nível do fator $\mathrm{t}_{\mathrm{Ac}}$ na resposta é dependente do nível do fator $t_{A c}$, portanto existe interação entre esses fatores. Os efeitos de interações $\left(\mathrm{t}_{\mathrm{Ac}} \mathrm{t}_{\mathrm{Ac}}\right)$ são superiores com o tempo de 60 min de incubação na formação do imunocomplexo, fato observado sobre a resposta (absorbância).

A partir das diluições e tempos de incubação definidos nas etapas de otimização, determinou-se o limiar de reatividade (“cut off”) para a proteína Tc85-11. A média aritmética das $\mathrm{A}_{450}$ de 10 amostras de soros padrões negativos $(0,317)$, acrescida de duas vezes o desvio médio $(0,027)$ das medidas de absorbância [17] resultou no valor de "cut off" de 0,371. O referido valor está representado na Figura 5 na forma de linha contínua; considerando $\pm 20 \%$, a zona de indeterminação está compreendida entre 0,445 e 0,297.

O emprego dessa proteína em imunoensaio ELISA indicou resposta positiva para os soros de pacientes chagásicos e reatividade cruzada com dois soros de leishmaniose (L2 e L3) e com o de paracoccidioidomicose (Figura 3). Soros de pacientes com artrite reumatóide e esquistossomose apresentaram resultados inconclusivos e correspondem às densidades ópticas dentro da zona de indeterminação de $\pm 20 \%$ tendo como base o limiar de reatividade de cada antígeno empregado no imunoensaio ELISA. Não se confirmou reação cruzada com soro de hanseníase.

Deve-se levar em consideração que o número de soros de pacientes chagásicos e de pacientes com outras patologias é considerado insuficiente para a validação do teste e que as reações cruzadas, principalmente com leishmaniose, descritas em diversos estudos com técnicas sorológicas, é a principal enfermidade infecciosa que interfere nos resultados sorológicos dando falsos positivos. Isto é atribuído ao fato de que os parasitos do gênero Leishmania pertencem à mesma 

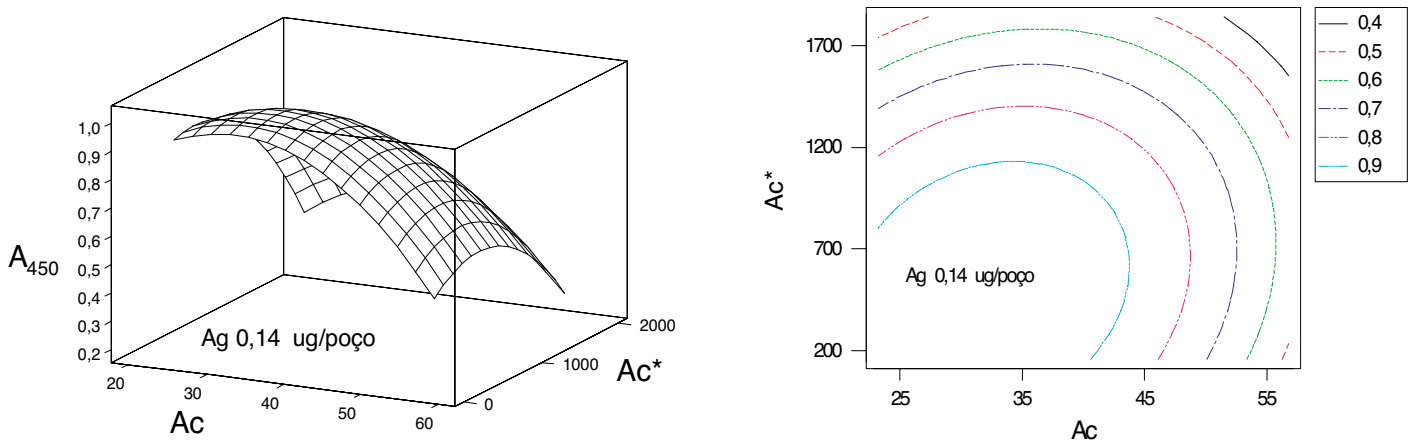

(a)
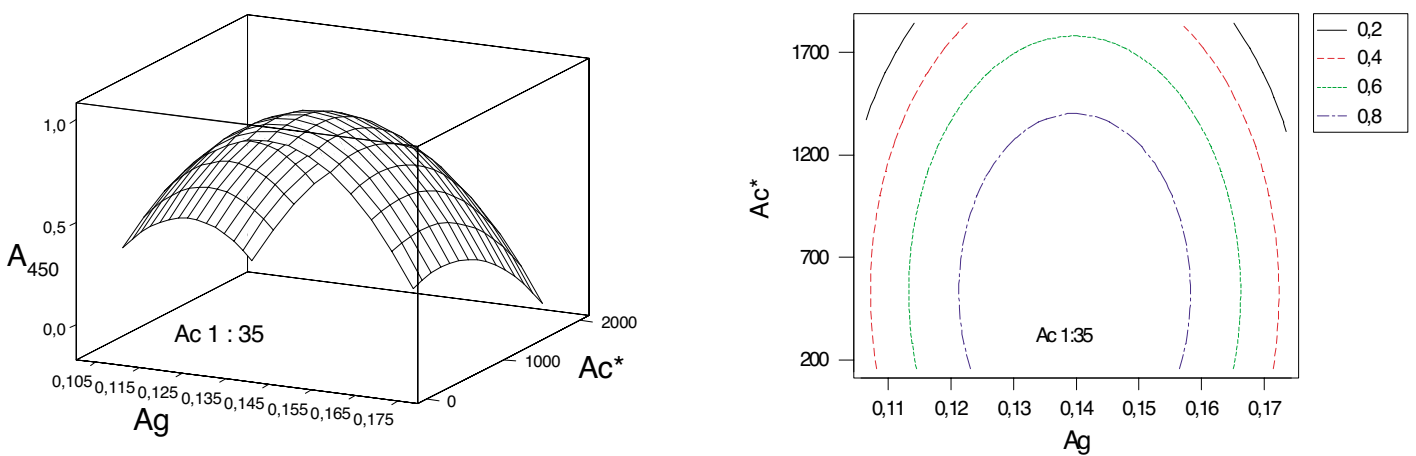

(b)
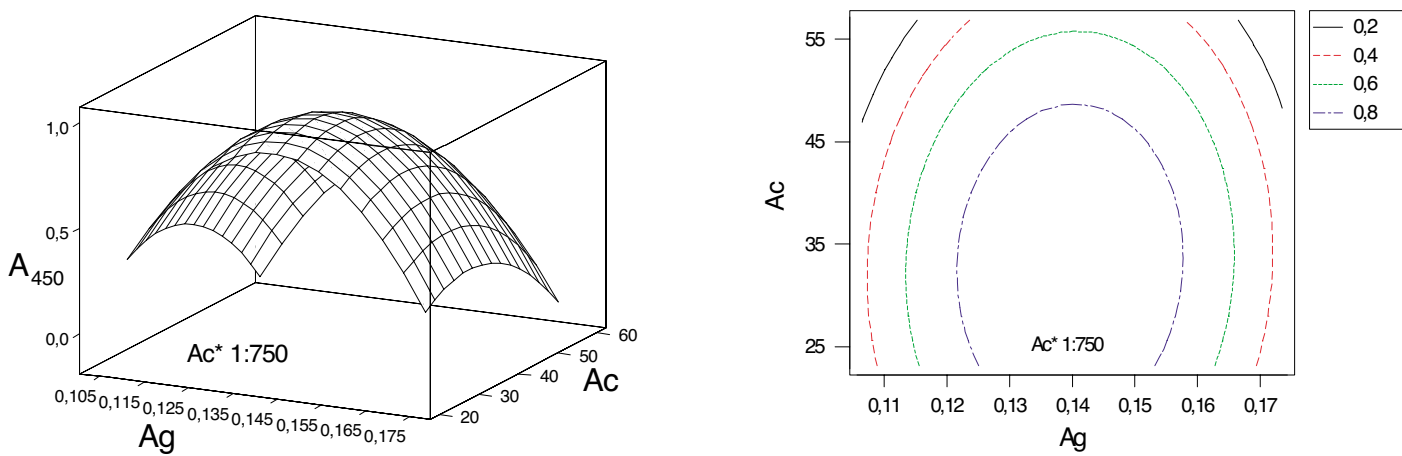

(c)

Figura 2. Superfícies de respostas tridimensionais e contornos bidimensionais obtidos pela análise do planejamento composto central: (a) diluições do Ac e Ac*; (b) diluições do Ag e Ac*; (c) diluições do Ag e Ac. 
Tabela 3. Matriz de planejamento do experimento fatorial $2^{2} \mathrm{e}$ valores de absorbância obtidos em diferentes tempos de incubação do imunoensaio ELISA empregando o antígeno Tc85-11.

\begin{tabular}{ccccc}
\hline $\begin{array}{c}\mathrm{N}^{\mathrm{o}} \\
\text { Ensaios }\end{array}$ & \multicolumn{2}{c}{ Variáveis } & $\begin{array}{c}\text { Resultado } \\
\text { (média) } \\
\mathrm{A}_{450}\end{array}$ & Desvio Padrão \\
\hline & $\mathrm{t}_{\mathrm{Ac}}$ & $\mathrm{t}_{\mathrm{Ac} *}$ & & \\
\hline 1 & 30 & 30 & 0,538 & 0,018 \\
3 & 60 & 30 & 0,624 & 0,016 \\
4 & 30 & 60 & 0,665 & 0,054 \\
\hline
\end{tabular}

Tabela 4. Matriz de planejamento do experimento fatorial $2^{2} \mathrm{e}$ valores de absorbância obtidos em diferentes tempos de incubação do imunoensaio ELISA empregando o antígeno Tc85-11.

\begin{tabular}{ccc}
\hline Variável & $\mathrm{T}$ & $\mathrm{P}$ \\
\hline $\mathrm{t}_{\mathrm{Ac}}$ & 7,17 & 0,002 \\
$\mathrm{t}_{\mathrm{Ac} *}$ & 9,10 & 0,001 \\
$\mathrm{t}_{\mathrm{Ac} . \mathrm{Ac} *}$ & 3,09 & 0,037 \\
\hline
\end{tabular}

$\mathrm{T}=$ Teste $\mathrm{T}$ (Gráfico de Pareto)

$\mathrm{P}=$ Probabilidade família de Trypanosomatidae, compartilhando os determinantes antigênicos. Cannova et al. [6] obtiveram reatividade cruzada com leishmaniose e malária empregando extrato bruto de epimastigotas $\left(8 \mu \mathrm{g} \mathrm{mL}^{-1}\right)$ e diluição do soro humano 1:100 em ELISA. A existência de reações cruzadas tem levado pesquisadores a procurar antígenos mais específicos, submetendo os parasitos obtidos nos cultivos a processos de purificação de seus componentes. O emprego de antígenos purificados tem elevado a especificidade das reações [7]. Esse aumento da especificidade em ELISA para o sorodiagnóstico da doença de Chagas foi estudado por

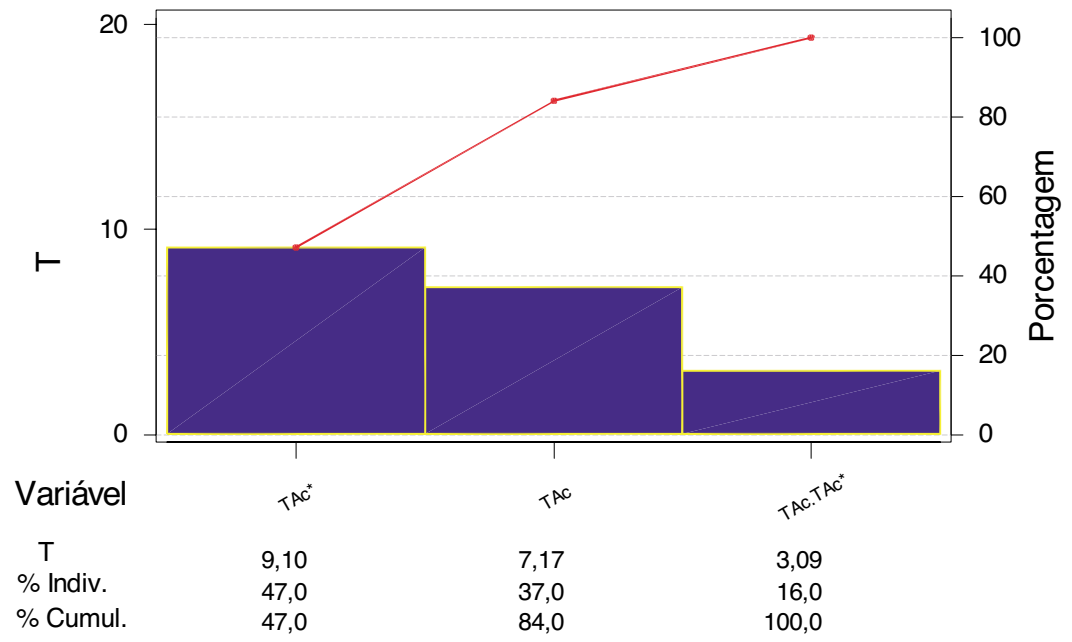

Figura 3. Gráfico de Pareto do planejamento fatorial $2^{2}$ para os tempos de incubações do Ac e Ac* (a linha vertical representa a porcentagem cumulativa das variáveis). 


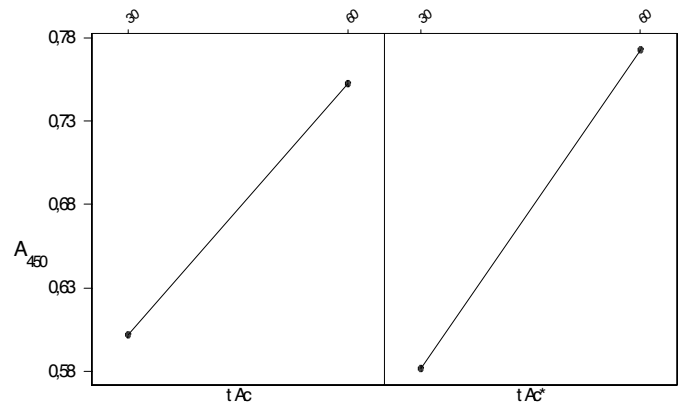

(a)

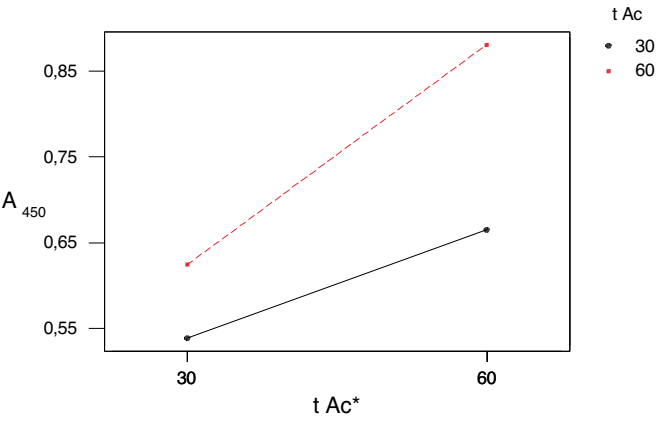

(b)

Figura 4. (a) Gráfico de efeitos principais dos tempos de incubações $\left(t_{A c}\right.$ e $\left.t_{A c^{*}}\right)$ e (b) gráfico de efeitos de interação $\left(\mathrm{t}_{\mathrm{Ac}} \mathrm{t} \mathrm{A}_{\mathrm{c}^{*}}\right)$ do planejamento fatorial $2^{2}$ sobre a resposta absorbância máxima no imunoensaio ELISA empregando o antígeno Tc85-11.

Umezawa et al. [8], empregando antígenos secretado-excretado de tripomastigota $\left(2 \mu \mathrm{g} \mathrm{mL}^{-1}\right)$, diluição do soro humano 1:200 e tempos de incubação de 60 minutos para as etapas de bloqueio, Ac e Ac*. Umezawa et al. [10] também estudaram a combinação de três antígenos recombinantes (B13, 1F8 e H49) de T. cruzi em ELISA, apresentando alta sensibilidade e especificidade nos testes sorológicos. Com a mistura de antígenos recombinantes de T. cruzi, CRA e FRA, Krieger et al. [9] obtiveram resultados satisfatórios quanto à sensibilidade em ELISA. Nesses trabalhos mencionados, empregando antígenos secretado-excretado e recombinantes de $T$. cruzi, não se verificou a reatividade cruzada com leishmaniose mediante a amostragem de soros examinada. A utilização simultânea de testes com antígeno bruto, preferencialmente com elevada sensibilidade, para contrabalançar a possível perda diagnóstica de alguns pacientes infectados que não apresentam, em seus soros, anticorpos contra os antígenos recombinantes [3] é aconselhável. Esses motivos adquirem mais relevância em Bancos de Sangue, que devem trabalhar com o máximo de sensibilidade. Portanto, os esforços devem ser dirigidos na busca de um antígeno que permita identificar verdadeiramente os anticorpos produzidos contra T. cruzi, empregando soros bem caracterizados para cada enfermidade.

\section{Conclusões}

Com base nos resultados obtidos, pode-se concluir que a proteína Tc85-11, envolvida na adesão e internalização do parasita à célula hospedeira, é também um antígeno que interage com o anticorpo anti-T. cruzi. O imunoensaio ELISA otimizado constitui mais uma ferramenta de trabalho no diagnóstico sorológico da doença de Chagas, porém esse antígeno também apresenta reação cruzada com leishmaniose.

No processo de otimização do imunoensaio ELISA, o emprego de planejamentos experimentais baseados em princípios estatísticos tornou-se importante para extrair do sistema em estudo o máximo de informações úteis, fazendo um número mínimo de experimentos. Além do que, as variáveis podem influenciar mutuamente e o valor ideal pode depender da interação entre as variáveis.

\section{Agradecimentos}

Agradecemos à FAPESP pelo apoio financeiro e a W. Colli, M. J. M. Alves, D. R. Oliveira que cederam a proteína Tc85-11.

Recebido em: 03/01/2006

Aceito em : 06/03/2006 
T. B. Zanoni, I. Z. Carlos, J. O. Tognolli, H. Yamanaka, A. A. P. Ferreira. Optimization of ELISA using Tc85-11 protein and factorial design.

\begin{abstract}
Chagas' disease is caused by the Trypanosoma cruzi (T. cruzi) and the detection of anti-T. cruzi antibodies in the serum is a method for diagnosis of the disease. In this work, indirect ELISA was optimized for detection of antibodies in patients' sera with Chagas' disease using Tc85-11 protein (Ag) from the trypomastigote surface of the parasite. The full factorial design for optimization of the experimental conditions was carried out for the incubation time, dilutions of $\mathrm{Ag}\left(0.08 \mathrm{mg} \mathrm{mL}^{-1}\right)$, primary antibody (Ac) and anti-IgG conjugated with peroxidase (Ac*) parameters. The best results were obtained with the following conditions: $0.14 \mathrm{mg} \mathrm{Ag} / \mathrm{well}, 60 \mathrm{~min}$ incubation time, dilutions of 1:35 and 1:1000 for Ac and $A c^{*}$, respectively. The cut off value was $\mathrm{A}_{450 \mathrm{~nm}}=0.371$. The indirect ELISA was applied to sera Chagas' disease infected patients samples and patients with different systemic diseases. Tc85-11 protein, which is involved in the adhesion of the parasite to host cell, is also suitable for serological diagnosis of Chagas' disease.
\end{abstract}

Keywords: T. cruzi; Tc85-11; ELISA; Chagas' disease.

\section{Referências}

[1] www.who.int/tdr/diseases/chagas/direction.htm. Acessado em 22/02/06.

[2] J. Costa, C.E. Almeida, E.M. Dotson, A. Lins, M. Vinhaes, A. C. Silveiras, C.B. Beard, Mem. Inst. Oswaldo Cruz 98(4) (2003) 443.

[3] Z. Brener, Z.A Andrade, M. Barral-Netto, Trypanosoma cruzi e doença de Chagas. 2. ed. Rio de Janeiro: Guanabara Koogan, 2000.

[4] S. L. M. Ávila, A. V. Ferreira, Diagnóstico laboratorial das principais doenças infecciosas e auto-imunes. Rio de Janeiro: Guanabara Koogan, 1996.

[5] A. Voller, C. Draper, D. E. Bidwell, A. Bartlett, Lancet 1 (1975) 426.

[6] D. C. Cannova, M. C. Aguilar, M. Pacheco, M. I. Simons, M. Medina, Rev. Fac. Cien. Salud. 6(3) (2002) 4.

[7] M. Schechter, A. O. Luquetti, J. M. Rezende, A. Rassi, M. A. Miles, Trans. Roy. Soc. Trop. Med. Hyg. 79 (1985) 637.

[8] E. S. Umezawa, M. S. Nascimento, A. M. S. Stolf, Diagn. Micr. Infec. Dis. 39(3) (2001) 169.

[9] M.A. Krieger, A. Almeida, W. Oelemann, J.J. Laffaille, J.B. Pereira, H. Krieger, M. R. Carvalho, S. Goldenberg, Am. J. Trop. Med. Hyg. 146(4) (1992) 427.

[10] E. S. Umezawa, S. F. Bastos, J. R. Coura, M. J. Levin,
A. Gonzalez, Rangel-Aldao R, B. Zingales, A. O. Luquetti, J. F. Silveira, Transfusion 43(1) (2003) 91.

[11] M. Marroquin-Quelopana, Jr. S. Oyama, T. A. Pertinhez, A. Spisni, M. A. Juliano, L. Juliano, W. Colli, M. J. M. Alves, Biochem. Biophys. Res. Com. 325 (2004) 612.

[12] A. A. P. Ferreira, W. Colli, M. J. M Alves, D. R. Oliveira, P.I. Costa, A.G. Güell, F. Sanz, A. V. Benedetti, H. Yamanaka, Bioelectrochem. 2005. Aceito para publicação.

[13] B. Barros Neto, I. S. Scarminio, R. E. Bruns. Como fazer experimentos: pesquisa e desenvolvimento na ciência e na indústria. 2. ed. Campinas: Editora da Unicamp, 2003.

[14] M Otto, Chemometrics: statistics and computer application in analytical chemistry. Toronto: Wiley-VCH, 1999.

[15] M. A. Johansson, K.E. Hellenas, Analyst 129(5) (2004) 438 .

[16] D. R. Oliveira, Caracterização de clones que codificam membros da família multigênica Tc85-11 de Trypanosoma cruzi. 98f. Tese (Doutorado em Bioquímica) - Instituto de Química, Universidade de São Paulo (USP), São Paulo, 2004. [17] A. A. P. Ferreira, Imunossensor amperométrico empregando a proteína Tc85-11 e investigações da interação da proteína com anticorpo anti-T. cruzi por microscopia de força atômica. 95 f. Tese (Doutorado em Biotecnologia) - Instituto de Química, Universidade Estadual Paulista (UNESP), Araraquara, 2005. 